Background and aims Appropriate hand hygiene among healthcare workers is the most important infection prevention measure; however, compliance is generally low. Gain-framed messages (i.e. messages that emphasise the benefits of hand hygiene rather than the risks of noncompliance) may be most effective. The aim of this study was to test the impact of gainframed messages on the frequency of handdisinfection events and compliance with the hand hygiene protocol.

Methods The study was conducted in a 27-bed neonatal intensive care unit. We performed an interrupted time series analysis of objectively measured hand disinfection events. We used electronic devices in hand alcohol dispensers, which continuously documented the frequency of hand disinfection events. In addition, hand hygiene compliance before and after the intervention period were directly observed.

Results The negative trend in hand hygiene events per patientday before the intervention (decrease by 2.3 [standard error, 0.5 ] per week) changed to a significant positive trend (increase of $1.5[0.5]$ per week) after the intervention $(p<0.001)$. The direct observations confirmed these results, showing a significant improved in hand hygiene compliance from 193 of 303 (63.6\%) observed hand hygiene events at pretest to 201 of $281(71.5 \%)$ at posttest $(\mathrm{p}=0.05)$.

Conclusions We conclude that gain-framed messages concerning hand hygiene presented on screen savers may improve hand hygiene compliance.

\section{0-134 NURSES' COMPLIANCE WITH PAIN ASSESSMENT IN THE PAEDIATRIC INTENSIVE CARE UNIT}

${ }^{1}$ NS Borst-Wezemer, ${ }^{1}$ WG Ista, ${ }^{2} \mathrm{M}$ van Dijk. 'Intensive Care, Erasmus MC-Sophia Children's Hospital, Rotterdam, Netherlands; Intensive Care and Neonatal Intensive Care, Erasmus MC-Sophia Children's Hospital, Rotterdam, Netherlands

\subsection{6/archdischild-2014-307384.201}

Background and aims Compliance with pain assessment in Paediatric Intensive Care Units is not always perfect. We aimed to identify factors explaining compliance or noncompliance with pain assessment in PICU patients.

Methods PICU nurses were asked 5 times to complete the same survey on pain management of the most critically ill child they cared for during the shift. Questions informed after the usefulness of pain assessment in this specific child, whether the nurse had assessed pain according to protocol, and any negative/positive impressions of the current shift. Relationships between compliance and these factors were evaluated with Fisher exact tests.

Results Ninety-three nurses returned 1 to 5 surveys (response rate $77 \%$ ), in total 407 surveys. The median working experience of the nurses $(94.6 \%$ females) at the PICU was 8 years (2 to 33 years). Pain was assessed in $89.4 \%$ of 406 surveys. Most shifts were perceived as positive (82\%), $10 \%$ as negative, 5\% mixed and $3 \%$ as neutral. Assessment yes/no was not significantly related to a negatively or positively experienced shift $(\mathrm{p}=0.82$ and 0.81 respectively). In $30 \%$ of surveys nurses considered assessment not useful but this was not significantly related to assessment yes/no $(\mathrm{p}=0.36)$.

Conclusions Compliance to pain assessment was acceptable. Whether non-compliance is primarily related to patient factors or nurse factors needs to be further unravelled. RETREIVAL: A NATIONAL REFERENCE SURVEY

DJ Hunt, GA Allison, P Turton, JR Tooley, JW Davis. Neonatal Intensive Care, St Michaels Hospital, Bristol, UK

\subsection{6/archdischild-2014-307384.202}

Background and aim The use of these safety measures during neonatal transport may reduce stress and improve physiological stability. There is no UK. national guidance for the use of specific measures such as restraints and ear defenders. As part of a quality improvement initiative we sought to benchmark these current safety practices by neonatal transport teams in the UK. Methods We surveyed all institutions undertaking neonatal transport in the UK. A questionnaire was devised and sent by email to the lead doctor and nurse of all 25 teams. We asked teams whether they used the safety measures in question and if so the specific type. We provided a section for open comment. An additional follow-up phone call was performed to complete or clarify information.

Results Twentyfour (96\%) of teams responded; 21/24 (88\%) used some form of restraint within transport. Three types of restraint are currently used within the U. K. Comments were provided regarding infection control and the safety effectiveness of restraints. Thirteen (54\%) respondents did not use ear defenders of any kind in any situation. In teams using ear defenders, 6/11 (55\%) used them in all situations and 2/11 (18\%) used them specifically for MRI and air transport. Respondents described difficulty in securing the defenders and concerns with effectiveness.

Conclusion These results show that within the UK there is a variation in neonatal transport safety practices, specifically in the use of restraints and ear defenders. This information will allow development and improvement of safe and secure transport practice.

\section{0-136 CONSULTING WITH CHILDREN PRIOR TO DESIGNING RESEARCH: IS IT REALLY WORTH THE EFFORT?}

${ }^{1} \mathrm{~B}$ Carter, ${ }^{2} \mathrm{C}$ Satchwell, ${ }^{3} \mathrm{~J}$ Simons, ${ }^{4} \mathrm{~L}$ Bray. ${ }^{1}$ School of Health, University of Central Lancashire, Preston, UK; ${ }^{2}$ School of Education and Social Science, University of Central Lancashire, Preston, UK; ${ }^{3}$ Faculty of Health and Social Care, The Open University, Milton Keynes, UK; ${ }^{4}$ Evidence-Based Practice Research Centre, Edge Hill University, Ormskirk, UK

\subsection{6/archdischild-2014-307384.203}

Background and aim Although many studies still either do not engage service users or only do so in a tokenistic way, service user engagement is now seen as best practice within research design. Not only is it respectful to engage service users, but it can also identify potential barriers, explore solutions and generate more robust research. In this paper we explore our experience of working with child service users as we developed a study exploring children's pain literacy.

Methods Using Appreciative Inquiry we worked with 38 children (5-17 years) in schools, hospitals and home settings. During our consultations with the children we explored the feasibility of the methods we were considering for data collection, asked them for suggestions of alternative approaches and explored core aspects of the observation element.

Results The children enjoyed the use of the collage-based data generation activities we planned. In response to our questions about whether they thought other children would feel safe 
Abstract 0-137 Table 1

\begin{tabular}{|c|c|c|c|c|c|c|c|}
\hline Study & $\begin{array}{l}\text { Eligible for } \\
\text { discussion with } \\
\text { parents (N) }\end{array}$ & Approached (N) & Consented (N) & Consent rate $(\%)$ & Time for screening (min) & Time for discussion (min) & $\begin{array}{l}\text { Mean time spent on screening } \\
\text { and discussions for each } \\
\text { consent participant (min) }\end{array}$ \\
\hline A & 97 & 75 & 72 & 95 & 20 & 30 & 58 \\
\hline B & 250 & 183 & 134 & 73 & 20 & 30 & 78 \\
\hline C & 261 & 99 & 10 & 10 & 30 & 45 & 1228 \\
\hline
\end{tabular}

talking about their pain; they felt that such would work best on a one-to-one basis or in small groups. They provided feedback on where we should position ourselves in ward settings whilst undertaking non-participant observation of children during the post-operative period. They made practical suggestions about how children could assent and withdraw from the study.

Conclusions From our experience our consultations were invaluable and worth the effort; our final design was more robust and grounded in the children's realities.

\section{0-137 SCREENING AND RECRUITMENT TO CLINICAL STUDIES ON A REGIONAL NEONATAL UNIT: A COMPARISON OF THREE STUDIES WITH CONTRASTING CHARACTERISTICS}

${ }^{1} \mathrm{P}$ McGowan, ${ }^{1} \mathrm{~J}$ Windrow, ${ }^{1} \mathrm{~K}$ Harvey, ${ }^{1} \mathrm{~B}$ Howell, ${ }^{2} \mathrm{MA}$ Turner. ${ }^{1}$ Neonatal Unit, Liverpool Women's NHS FT, Liverpool, UK; ' Women's and Children's Health, University of Liverpool, Liverpool, UK

\subsection{6/archdischild-2014-307384.204}

Introduction The resources required to recruit neonatal studies are thought to be greater than for other studies but have not been formally described to date. The aim of this report is to summarise our experience of the effort required to recruit neonates to studies and our success rate with recruitment.

Methods Three contrasting studies were selected from our portfolio. The numbers of babies that were eligible, approached and consented were extracted from our screening logs. The rate of consent among families who were approached was calculated. The time taken for each step was assessed for a selection of families and scaled up for the whole study.

Results Study A was a non-interventional study requiring daily faecal samples. Study B involved taking dried blood spots for pharmacokinetic assays of medication used as routine clinical practice. Study C was a first-in-human study of a novel medicine. Key metrics are summarised in the Table.

The total times spent do not reflect time spent looking for parents or staff.

Discussion Recruitment to neonatal clinical studies requires considerable time, effort and teamwork. The consent rate differs according to the intensity of the study. Funders should take account of screening and recruitment times.

\section{Nursing Team and Parenting}

\section{0-138 THE IMPACT OF PARENTING STYLE ON JORDANIAN ADOLESCENTS' WELL-BEING IN THE NORTH OF JORDAN}

A Al-Anati. Community and Mental Health, Jordan University of Science and Technology, Irbid, Jordan

10.1136/archdischild-2014-307384.205
Background and aims Parenting is a complex activity includes specific practices that affect on adolescents 'development. This study aimed to describe the types of parenting styles among Jordanian adolescents in the north of Jordan. As well as, to examine the relationship between parenting style and adolescents' well-being (general mental health, self - esteem, and schools' achievement.

Methods A cross sectional design was used to collect data from 500 students in the age of 13-16 years old (8th, 9th, 10th) classes in the period between April and May, 2012. Parenting Authority Questioner (Buri, 1991), General Health Questioner (Golderberg, 1988), Hare self-esteem scale (Hare, 1985) were used in this study. Clusters random sample was used to select the elements from public and private schools of the three educational directorates of Irbid Governorate.

Results 222 (44.4\%) male, and 278(55.6\%) female students participated in this study. The results of this study showed the means of authoritative parenting style was 35.3 ( $\mathrm{Sd}=5.7$ ), authoritarian style was $31.6(\mathrm{Sd}=4.1)$, and permissive parenting style was $(\mathrm{Sd}=4.6)$ (33.3) with scale range $=10-50)$. The results showed a negative correlation between three types of parenting styles, and adolescents mental health. A positive correlation found between the three types of parenting styles, and adolescents' self-esteem. However, there was significant differences between three types of parenting styles, and adolescents GPA.

Conclusion Jordanian parenting styles had positive impact on adolescents' self-esteem, and academic achievements, while, it had negative impact on adolescents' mental health.

\section{0-139 GIVING VOICE TO THE EXPERIENCES OF FIRST-TIME FATHERS OF LATE PRETERM INFANTS: A QUALITATIVE STUDY}

${ }^{1} \mathrm{~K}$ Benzies, ${ }^{2} \mathrm{~J}$ Magill-Evans. ${ }^{1}$ Faculty of Nursing, University of Calgary, Calgary, Canada; ${ }^{2}$ Faculty of Rehabilitation Medicine, University of Alberta, Edmonton, Canada

\subsection{6/archdischild-2014-307384.206}

The transition to fatherhood can generate a range of cognitive and emotional experiences. The purpose of this study was to explore the experiences of first-time fathers of late preterm (34 to 36 weeks gestation) infants. The study was part of a larger randomised controlled trial to test a video-modelled play intervention for fathers that was delivered during home visits. At the outcome home visit ( 8 months corrected age) we used structured interviews with 85 fathers to explore the joys and challenges of fathering a late preterm infant. The interviews were transcribed and analysed using a thematic approach. Three main themes about fathers' experiences emerged. Fathers believed that spending time with the baby, watching the baby grow and learn, and being recognised by the baby contributed to fathering being the "best job in the world." Specific concerns about keeping the baby safe, meeting developmental milestones, self-confidence in 